\title{
ANÁLISE CRÍTICA DA INCLUSÃO SOCIAL NO MERCADO DE TRABALHO DAS PESSOAS COM DEFICIÊNCIA
}

\author{
Fabio Augusto Martinello ${ }^{1}$ \\ Wilmar Andolfato Scavassa ${ }^{2}$ \\ Andrea Luiza Escarabelo Sotero ${ }^{3}$
}

RESUMO: O presente artigo tem como enfoque demonstrar a empregabilidade e a

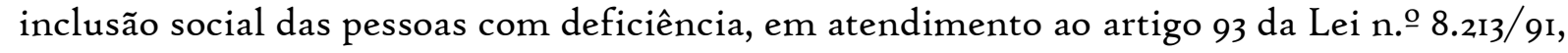
que estabeleceu cotas para contratação de Pessoas com Deficiência nas empresas. O estudo realizará uma análise crítica com o intuito de desconstruir a imagem do indivíduo deficiente como incapaz, desprovido de qualidades e oneroso, demonstrando outra faceta de que é indivíduo capaz, produtivo, dotado de qualificação profissional, sendo um trabalho árduo e lento, que deve ser compreendido com um compromisso social de diversas áreas, quando se pensa em promover condições mais igualitárias para o desenvolvimento humano e criar condições para que o contexto o qualifique, favorecendo o estabelecimento de interações sociais. O trabalho demonstrará a importância da inclusão social das pessoas com deficiência no mercado de trabalho, promovendo a diversidade, respeitando as diferenças individuais, com o intuito de reduzir as desigualdades sociais.

Palavras-chave: Pessoa com deficiência. Empregabilidade. Inclusão social.

\section{INTRODUÇÃO}

O Brasil possui significativa população de pessoas com deficiências, sendo que a participação destas pessoas no mercado de trabalho merece destaque, a fim de que seja

\footnotetext{
I Discente do Curso de Direito - IESB - Instituto de Ensino Superior de Bauru - E-mail: fabiomartinellorsı@gmail.com.

${ }^{2}$ Docente do Curso de Direito e Psicologia - IESB - Instituto de Ensino Superior de Bauru - e-mail: wascavassa@hotmail.com.

3 Docente Mestre do Curso de Direito - IESB Instituto de Ensino Superior de Bauru - e-mail: andrea.escarabelo@universidadebrasil.edu.br.
} 
dado a real amplitude da expressão "inclusão" através da atividade profissional, que é mecanismo primordial da dignidade da pessoa humana.

A busca por uma sociedade inclusiva, assume a necessidade de adequação de inúmeras divergências sociais e culturais, bem como modificações relevantes no ordenamento jurídico.

Nesse sentido, o presente artigo ventilará a evolução do ordenamento jurídico brasileiro, com a aplicação objetiva da Constituição Federal e da Lei que dispõe sobre os benefícios da Previdência Social, bem como sobre a inserção do sistema de cotas no setor privado, sopesando mecanismos e incentivos de cumprimento da legislação com ações afirmativas.

Para elaboração do presente, será utilizado o método dedutivo, eis que primeiramente será abordado elementos fundamentais para análise do tema, e posterior discussão e conclusão.

\section{EVOLUÇÃO DO ORDENAMENTO JURÍDICO EM RELAÇÃO AOS DIREITOS DA PESSOA COM DEFICIÊNCIA}

Inicialmente, imperioso mencionar que a primeira alusão constitucional sobre a pessoa com deficiência encontra-se na Constituição de 1967 , em razão da Emenda Constitucional n.으 oI/1969, que alterou o art. 175, $\$ 4^{\circ}$, vejamos:

Art. 175. A família é constituída pelo casamento e terá direito à proteção dos Podêres Públicos.

$\S 4^{\underline{O}}$ Lei especial disporá sôbre a assistência à maternidade, à infância e à adolescência e sôbre a educação de excepcionais.

Manoel Gonçalves Ferreira Filho (FERREIRA FILHO, 1986, p. 702), conceituou de "excepcional" que está mencionado no artigo supra "aqueles que por motivos físicos ou mentais se encontram em situação de inferioridade em relação aos chamados 'normais"”. Pontes de Miranda (MIRANDA, 1972, p. 333), destacou que: "excepcionais está, aí, por 
pessoas que, por faltas, ou defeitos físicos ou psíquicos, ou por procedência anormal (nascido, por exemplo, em meio social perigoso), precisam de assistência”.

Entretanto, a terminologia "excepcional" trazia em sua essência o preconceito de que essas pessoas eram dispensáveis, inúteis e desprovidas de valor para a sociedade, sendo que, com o passar do tempo, em razão dos movimentos sociais, debates entre organizações sociais, civis, governamentais e entidades de defesa dos direitos da pessoa com deficiência e com a participação efetiva de todas essas pessoas na elaboração de documentos oficiais que foram incluídos aos internacionais, a terminologia foi substituída por portador de deficiência ou pessoa com deficiência, que têm a aprovação da ONU, por serem mais adequadas ao se referirem a pessoas com deficiência e por estarem desprovidas de qualquer carga de discriminação.

Ao longo da história da humanidade, houve uma grande mudança terminológica, demonstrando o avanço da sociedade e da ideia das barreiras que foram quebradas na sociedade.

Atualmente, o conceito de deficiência abrange todas as formas de limitação física, 921 mental, auditiva, sensorial, de natureza permanente ou transitória, que de alguma forma dificulte e restrinja o acesso e a permanência a direitos e garantias como, educação, trabalho, esporte, lazer, e a realização de tarefas essenciais à vida diária.

A Emenda Constitucional n.ำ 12 , de $17 /$ Io/1978, introduziu no ordenamento jurídico a proteção ao deficiente quanto a educação, assistência, reabilitação e reinserção na vida econômica e social, e ainda, abordou o princípio da não discriminação e a questão da acessibilidade da pessoa com deficiência aos edifícios e logradouros públicos.

\footnotetext{
Artigo único - É assegurado aos deficientes a melhoria de sua condição social e econômica especialmente mediante:

I - educação especial e gratuita;

II - assistência, reabilitação e reinserção na vida econômica e social do país;

III - proibição de discriminação, inclusive quanto à admissão ao trabalho ou ao serviço público e a salários;

IV - possibilidade de acesso a edifícios e logradouros públicos.
}

Com a promulgação da Constituição Federal de 1988, apresentou um marco para os direitos sociais no Brasil, pois preocupou em garantir o direito à igualdade de forma ampla 
e de proteger as pessoas em situações desvantajosas, seja por questões raciais, socioeconômicas ou em razão de alguma deficiência, dando abertura para a integração e inclusão social da pessoa com deficiência.

O artigo Io da Constituição Federal, elenca como fundamentos da República Federativa do Brasil: "I - a soberania; II - a cidadania; III - a dignidade da pessoa humana; IV - os valores sociais do trabalho e da livre iniciativa; V - o pluralismo político”, sendo que o art. $3^{\text {o}}$, traça os seguintes objetivos:

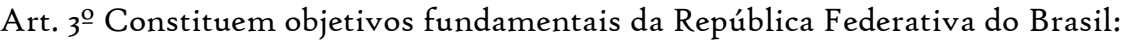
I - construir uma sociedade livre, justa e solidária; II - garantir o desenvolvimento nacional;

III - erradicar a pobreza e a marginalização e reduzir as desigualdades sociais e regionais;

IV - promover o bem de todos, sem preconceitos de origem, raça, sexo, cor, idade e quaisquer outras formas de discriminação.
}

Observa-se, que analisando os fundamentos e objetivos indicados na Carta Magna, verificamos a intenção de um Estado ativo e compromissado em viabilizar uma vida digna para todos os cidadãos, sem exceção, sendo que no art. $7^{\circ}$, inciso XXXI, prevê expressamente o rol de direitos dos trabalhadores urbanos e rurais e a não discriminação da pessoa com deficiência:

Art. $7^{\text {o }}$ São direitos dos trabalhadores urbanos e rurais, além de outros que visem à melhoria de sua condição social:

XXXI - proibição de qualquer discriminação no tocante a salário e critérios de admissão do trabalhador portador de deficiência;

O art. 208, inciso III da Carta Magna menciona sobre a integração da pessoa deficiente nas escolas regulares de ensino, com intuito de afastar a discriminação e incentivar a socialização, vejamos:

Art. 208. O dever do Estado com a educação será efetivado mediante a garantia de:

III - atendimento educacional especializado aos portadores de deficiência, preferencialmente na rede regular de ensino.

No cenário dos Direitos Humanos, a Declaração de Salamanca em 1994, na cidade de Salamanca (Espanha) merece destaque, pois introduziu uma inovação mundial que teve por objetivo apontar aos países a necessidade de inserção de políticas públicas e 
educacionais que atendessem todas as pessoas de modo igualitário, independente das suas condições pessoais, sociais, econômicas e socioculturais.

Portanto, a Declaração de Salamanca inspirou no desenvolvimento do pensar inclusivo, bem como no processo de acessibilidade da pessoa com deficiência, como uma forma de alcançar uma educação de qualidade e formar uma sociedade menos preconceituosa e mais inclusiva, visando demonstrar uma inclusão social que atinge a todos e não somente aos deficientes.

$\mathrm{O}$ art. 227 da Constituição Federal apresenta questões relacionadas aos direitos da pessoa com deficiência, demonstrando o dever de ser compartilhada com a família, sociedade e Estado:

Art. 227. É dever da família, da sociedade e do Estado assegurar à criança, ao adolescente e ao jovem, com absoluta prioridade, o direito à vida, à saúde, à alimentação, à educação, ao lazer, à profissionalização, à cultura, à dignidade, ao respeito, à liberdade e à convivência familiar e comunitária, além de colocá-los a salvo de toda forma de negligência, discriminação, exploração, violência, crueldade e opressão.

§ I - - O Estado promoverá programas de assistência integral à saúde da criança e do adolescente, admitida a participação de entidades não governamentais e obedecendo os seguintes preceitos:

II - criação de programas de prevenção e atendimento especializado para as pessoas portadoras de deficiência física, sensorial ou mental, bem como de integração social do adolescente e do jovem portador de deficiência, mediante o treinamento para o trabalho e a convivência, e a facilitação do acesso aos bens e serviços coletivos, com a eliminação de obstáculos arquitetônicos e de todas as formas de discriminação.

§ 2o A lei disporá sobre normas de construção dos logradouros e dos edifícios de uso público e de fabricação de veículos de transporte coletivo, a fim de garantir acesso adequado às pessoas portadoras de deficiência.

É importante destacarmos a diferença da palavra integração e inclusão para melhor compreensão da inserção no mercado de trabalho das pessoas portadoras de deficiência, onde a integração privilegia o aluno portador de necessidades educativas especiais, dividindo com ele a responsabilidade da inserção, enquanto a inclusão tem o intuito de exigir da sociedade, condições para essa inserção.

Nesse sentido, Sassaki (1997, p. 39) faz distinção entre as noções de integração e inclusão social: "a integração seria a mera inserção formal da pessoa na sociedade, enquanto a inclusão equivaleria à modificação da sociedade para acolhê-la, permitindo seu desenvolvimento e seu pleno exercício da cidadania”. 
A inclusão da pessoa com deficiência inicia-se da relação familiar, ato contínuo, extrapola para o âmbito da comunidade, sendo que somente caberá ao Estado, o cumprimento das normas dispostas na Constituição e na legislação infraconstitucional.

Cláudia Werneck (200I) ${ }^{4}$ ensina que o direito à inclusão é legitimado na condição que somos, enquanto humanos afirmando que:

\begin{abstract}
O conceito de inclusão nos ensina não a tolerar, respeitar ou entender a deficiência, mas sim a legitimá-la, como condição inerente ao conjunto "humanidade". Uma sociedade inclusiva é aquela capaz de contemplar sempre, todas as condições humanas, encontrando meios para que cada cidadão, do mais privilegiado ao mais comprometido, exerça o direito de contribuir com seu melhor talento para o bem comum analisa.
\end{abstract}

Nesse sentido, não há dúvidas que o Estado Brasileiro tem uma preocupação quanto a política social voltada em prol da proteção dos direitos das pessoas portadoras de deficiência, bem como a sua inclusão, uma vez que é baseada em uma sociedade livre, justa e solidária, motivo pelo qual, a inclusão das pessoas portadoras de deficiência é um dever constitucional, não podendo a sociedade se distanciar deste cumprimento.

A questão da acessibilidade da pessoa com deficiência merece destaque, pois tem por objetivo afastar as barreiras arquitetônicas, visando a inclusão da pessoa com deficiência, proporcionando acesso às escolas, aos hospitais e, em especial, aos locais de trabalho, sendo que a Constituição Federal apresenta instrumentos de proteção e garantia dos direitos fundamentais das pessoas deficientes, citando por exemplo, o mandado de segurança coletivo (art. $5^{\circ}$, inciso LXX) e a ação civil pública (art. 129, inciso III).

Portanto, verifica-se que a Carta Magna de 1988 estabeleceu de forma significativa proteção à pessoa com deficiência, seja no setor público ou no privado, bem como é específica quanto à igualdade dos trabalhadores.

\title{
3 PRINCÍPIO CONSTITUCIONAL DA IGUALDADE
}

Analisando as conquistas das pessoas com deficiência e que foram protegidas na Constituição Federal de 1988, importante ventilar considerações acerca do princípio da

\footnotetext{
${ }^{4}$ Disponível em: http://www.educacional.com.br/entrevistas/entrevistaoo73.asp. Acesso em 28 set 2020.
} 
igualdade, insculpido no art. $5^{\circ}$, caput, sendo que para melhor compreensão, torna-se necessário esclarecer as diferenças entre a igualdade formal e igualdade material.

A concepção de igualdade decorreu da Revolução Francesa e possuía caráter eminentemente formal, no sentido de que a igualdade deveria ser observada quando da aplicação das leis, ou seja, destinava-se apenas ao aplicador da norma, que deveria aplicar a todos indistintamente, não aceitando a concessão de privilégios ou distinções.

Segundo o conceito de Norberto Bobbio (1992, p. 34) e da Declaração Universal, todos os homens nascem iguais na liberdade, sendo assim, deve ser excluído todo o tipo de discriminação fundadas em diferenças específicas:

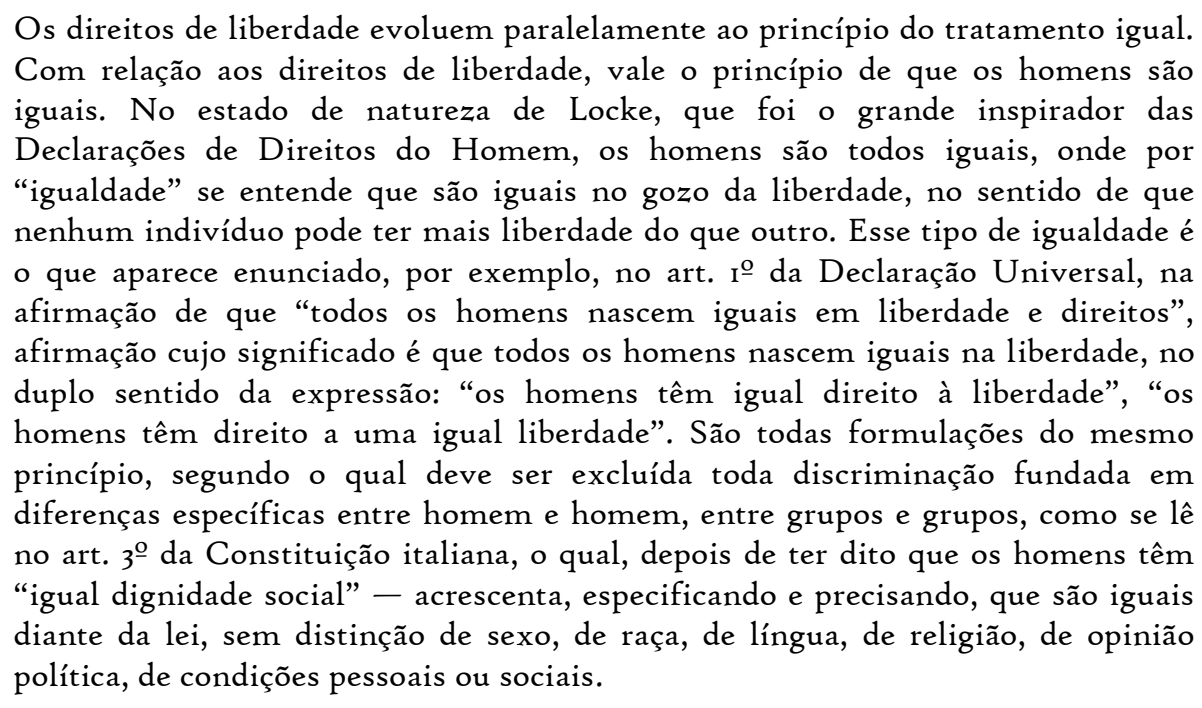

A igualdade formal não abordou a questão da adoção de medidas que reduzissem as discrepâncias sociais e econômica entre todos os cidadãos, não conferindo proteção especial a determinados indivíduos, em especial, as pessoas com deficiência, tendo apenas se limitado a aplicar a regra a todos os indivíduos perante a lei.

Entretanto, a igualdade meramente formal foi afastada ao final do século XIX, ao constatar uma enorme desigualdade social na Europa, inexistindo qualquer proteção legal aos trabalhadores, ante a execução de extensas jornadas de trabalho, em ambientes sem respeito à dignidade humana, sendo que naquele momento histórico, a força de trabalho era considerada mercadoria.

Luiz Alberto David Araújo (ARAÚJO, 1977, p. 45) defende que: 
[...] a igualdade formal deveria ser quebrada diante de situações que, logicamente, autorizam tal ruptura. Assim, o princípio da igualdade não permite o tratamento desigual entre pessoas na mesma situação, mas permite tratamento desigual (igualar as desigualdades) entre pessoas que estão em situações diferentes. É importante assinalar que, às vezes, as pessoas (homens/ mulheres, deficientes/não deficientes) devem ser tratadas igualmente porque estão na mesma situação e, às vezes, devem ser tratadas desigualmente porque estão em situações diferentes.

Com o advento das manifestações operárias do início do século $\mathrm{XX}$, o anseio de uma igualdade material e real foi marcante, pois idealizavam desigualar para que fosse alcançada a igualdade, conferindo proteção especial aos direitos de certas pessoas ou grupos, consoante esclarecimento de Manoel Jorge da Silva Neto (SILVA NETO, 20or, p. 52).

[...] destarte, o fenômeno da positivação constitucional dos elementos socioideológicos tem por causa eficiente a própria questão social, porquanto floresceu o capitalismo em regime de concentração dos meios de produção e também da insidiosa realidade encarado como mercadoria, além da adversidade de condições em que era prestado.

A necessidade de uma igualdade real direcionou a atenção dos legisladores quanto às necessidades de determinados grupos sociais, tais como: pessoas com deficiências, idosos, crianças, etc, sendo que a Constituição Federal de 1988 enfatizou o Princípio da Igualdade em inúmeros dispositivos legais, dispondo medidas para sua concretização, proibindo de toda e qualquer forma de discriminação, seja em razão da raça, cor, sexo, religião, deficiência, ou ainda em razão de qualquer forma de diferença.

Claudio José Amaral Bahia e Wilson Kobayashi (2003, p.45) citam em sua obra que:

Uma das grandes preocupações em relação à necessidade de efetivação da dignidade da pessoa humana e, consequentemente, da concretização do princípio da igualdade no seio social, diz respeito às minorias, as quais, seja em razão de apresentarem comportamento diferenciado daquele normalmente experimentado por uma determinada comunidade, seja em razão de não ostentarem as mesmas características físicas e psíquicas verificadas na maioria dos indivíduos, sofrem os mais diversos tipos de discriminação e de exclusão, sendo, inclusive, expungidas injustamente do benefício resultante do exercício de direitos que, ao menos em tese, se mostram pertencentes a qualquer cidadão.

Com o passar dos anos, certas discriminações encontravam-se entrelaçadas à cultura e à sociedade, sendo que a mera incorporação do princípio da igualdade no texto constitucional e a expressa vedação de praticas discriminatórias não seriam suficientes 
para impedir as desigualdades existentes na sociedade, havendo a necessidade do uso de medidas e políticas estatais ou privadas, visando a redução do processo discriminatório e seus efeitos nocivos através de ações afirmativas, que nasceram na década de 1960, nas cortes superiores norte-americanas, consoante Carmen Lúcia Antunes Rocha (ROCHA, 1996, p. 285), explica o surgimento da expressão "ação afirmativa":

\begin{abstract}
A expressão ação afirmativa, utilizada pela primeira vez numa ordem executiva federal norte-americana do mesmo de 1965, passou a significar, desde então, a exigência de favorecimento de algumas minorias socialmente inferiorizadas, vale dizer, juridicamente desigualadas, por preconceitos arraigados culturalmente e que precisavam ser superados para que se atingisse a eficácia da igualdade preconizada e assegurada constitucionalmente na principiologia dos direitos fundamentais.
\end{abstract}

Observa-se que as ações afirmativas foram consideradas como medidas para compensar a inferioridade econômica e social de certas minorias através do intermédio de políticas de garantia de emprego, no âmbito público ou privado, sem que afastasse o direito das maiorias, objetivando valorizar e aumentar a participação dos grupos minoritários, a fim de garantir a plenitude de direitos e a efetiva igualdade perante a sociedade.

Segundo Bobbio (2008, p. 359), a desigualdade torna-se instrumento de igualdade para corrigir uma desigualdade anterior, sendo a nova igualdade o resultado da equiparação de duas desigualdades.

As políticas de ações afirmativas visam atingir a igualdade mediante o tratamento diferencial e positivamente privilegiado de indivíduos pertencentes a determinados grupos, vítimas de discriminação negativa e difusa, objetivando combater a própria discriminação, através da discriminação positiva para garantir a inclusão social pela igualdade de oportunidades.

As práticas discriminatórias podem ser perpetradas, tanto no setor público quanto no privado, de forma que, por isso, as políticas de ações afirmativas podem ser públicas ou privadas. Um exemplo claro de ação afirmativa no setor público é a fixação de reserva de até $20 \%$ (vinte por cento) das vagas oferecidas em concurso, conforme dispõe a Lei n. $8.112 / 90$ em seu art. $5^{\circ}$. 
Deste modo, o critério de cálculo de vagas reservadas às pessoas portadoras de necessidades especiais deve se orientar pela máxima efetividade da norma constitucional, garantindo-se as vagas das pessoas portadoras de necessidades especiais.

Nessa linha de raciocínio, a ideia de igualdade de tratamento foi quebrada, pois o portador de deficiência tem, pela sua própria condição, direito à quebra da igualdade, em situações nas quais participe com pessoas sem deficiência. Portanto, temos que a proteção à dignidade da pessoa humana se viabiliza pelo tratamento isonômico a ser dado a todos os homens, no sentido de que a preservação do direito da igualdade está implícita no direito à integração da pessoa portadora de deficiência.

Assim, podemos concluir que as ações afirmativas foram mecanismos compensatórios utilizados para inserção de determinados grupos sociais no exercício do direito ao trabalho, citando como exemplo: sistema de cotas, concessão de benefícios e subsídios às empresas, deduções, etc.

No Brasil, adotou-se o sistema de cotas para a reserva de mercado de trabalho às pessoas com deficiência nos concursos públicos e nas empresas privadas com mais de cem 928 empregados, não sendo possível substituir a reserva de vagas por eventual contribuição monetária destinada a um fundo, ao passo que se exige a vinculação direta do empregador com a pessoa portadora de deficiência, tratando-se de uma ação afirmativa, o sistema de cotas para inclusão da pessoa deficiente ao mercado de trabalho.

Isto porque, mesmo diante de dispositivo legal, há desigualdade causada pela limitação (própria da deficiência), associada ao preconceito, o qual gera a exclusão social e por este motivo, há a necessidade das cotas ou de outros incentivos que visem a inclusão no mercado de trabalho.

\section{DO SISTEMA DE RESERVA DE VAGAS/COTAS NO SETOR PRIVADO}

Conforme mencionado anteriormente, o Brasil aderiu ao sistema de cotas ou reserva legal para estimular e garantir a inclusão da pessoa com deficiência ao mercado de trabalho, no qual devemos reconhecer que se trata de uma tarefa árdua e envolve diversos aspectos, tais como: educação, qualificação, eliminação de barreiras arquitetônicas, 
adequação do ambiente de trabalho, conforme preleciona Joaquim B. Barbosa Gomes (GOMES, 200I, p.40).

A Lei n. 8.213/91 que introduziu a reserva de mercado ou sistema de cotas, garantindo o direito de acesso ao mercado de trabalho das pessoas portadoras de deficiência:

Art. 93. A empresa com roo (cem) ou mais empregados está obrigada a preencher de $2 \%$ (dois por cento) a $5 \%$ (cinco por cento) dos seus cargos com beneficiários reabilitados ou pessoas portadoras de deficiência, habilitadas, na seguinte proporção:

I - até 200 empregados............2\%

II - de 201 a 50o........................ $3 \%$

III - de 20I a rooo.....................4\%

IV - de roor em diante............5\%.

O Decreto n. $\stackrel{\circ}{3.298}$, de 20 de dezembro de 1999 regulamentou a Lei n. 0 7.853, de 24 de outubro de 1989, apresentando disposições adicionais relativas ao conceito da pessoa com deficiência no art. $4^{\mathrm{O}}$ e $36^{\circ}$, cujo rol é restritivo, vejamos:

Art. $4^{\underline{o}}$ - É considerada pessoa portadora de deficiência a que se enquadra nas seguintes categorias:

I - deficiência física - alteração completa ou parcial de um ou mais segmentos do corpo humano, acarretando o comprometimento da função física, apresentando-se sob a forma de paraplegia, paraparesia, monoplegia, monoparesia, tetraplegia, tetraparesia, triplegia, triparesia, hemiplegia, hemiparesia, ostomia, amputação ou ausência de membro, paralisia cerebral, nanismo, membros com deformidade congênita ou adquirida, exceto as deformidades estéticas e as que não produzam dificuldades para o desempenho de funções;

II - deficiência auditiva - perda bilateral, parcial ou total, de quarenta e um decibéis $(\mathrm{dB})$ ou mais, aferida por audiograma nas frequências de $500 \mathrm{HZ}$, I.00oHZ, $2.000 \mathrm{~Hz}$ e $3.000 \mathrm{~Hz}$;

III - deficiência visual - cegueira, na qual a acuidade visual é igual ou menor que o,o5 no melhor olho, com a melhor correção óptica; a baixa visão, que significa acuidade visual entre 0,3 e 0,05 no melhor olho, com a melhor correção óptica; os casos nos quais a somatória da medida do campo visual em ambos os olhos for igual ou menor que 6oo; ou a ocorrência simultânea de quaisquer das condições anteriores;

IV deficiência mental - funcionamento intelectual significativamente inferior à média, com manifestação antes dos dezoito anos e limitações associadas a duas ou mais áreas de habilidades adaptativas, tais como:
a) comunicação;
b) cuidado pessoal;
c) habilidades sociais;
d) utilização da comunidade;
d) utilização dos recursos da comunidade;
e) saúde e segurança;
f) habilidades acadêmicas; 


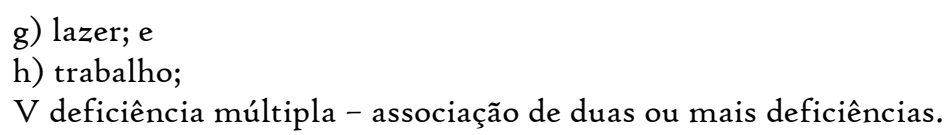

Art. 36, § 20 Considera-se pessoa portadora de deficiência habilitada aquela que concluiu curso de educação profissional de nível básico, técnico ou tecnológico, ou curso superior, com certificação ou diplomação expedida por instituição pública ou privada, legalmente credenciada pelo Ministério da Educação ou órgão equivalente, ou aquela com certificado de conclusão de processo de habilitação ou reabilitação profissional fornecido pelo Instituto Nacional do Seguro Social INSS.

Entretanto, contratar uma pessoa com deficiência, na maioria das vezes, implica na realização de modificações arquitetônicas da empresa, aquisição de equipamentos específicos e treinamento de pessoal, tornando o projeto oneroso para o empregador, sendo que a justificativa para os empresários é a falta de pessoas deficientes aptas para o desempenho de determinadas funções, ou que o quadro de empregados estaria preenchido. Do outro lado, o sistema de assistência social proporciona as pessoas com deficiência, benefício de prestação continuada ou auxílio-doença, que são incompatíveis com o assalariamento decorrente de um vínculo formal de emprego e por este motivo, muitas pessoas com deficiência optam em não trabalhar formalmente (seja em razão de baixos salários decorrentes de problemas com qualificação profissional), a fim de que o benefício não seja suspenso.

Todavia, este pensamento deve ser modificado, no sentido de que efetivamente seja praticada a inclusão, visando oportunizar às pessoas com deficiência não apenas o ingresso formal no mercado de trabalho, mas também a experiência de compartilhamento de expectativas, tratamento, oportunidades, além de qualificação e ascensão profissional, almejando uma inclusão não apenas funcionalista, mas sim, influenciada pelo princípio da dignidade da pessoa humana.

A não-utilização da vaga reservada para a pessoa com deficiência, mesmo a inscrita em tal condição (vaga reservada), obedece estritamente ao princípio da inclusão social e da dignidade da pessoa humana. Dessa forma, o nosso ordenamento jurídico ao assegurar cotas para deficientes, determinadas por lei específica, cria uma oportunidade para corrigir uma desigualdade real. 
Contudo, devemos observar que o sistema de cotas não pode ser utilizado de maneira isolada, pois revela-se ineficiente promover a inserção da pessoa com deficiência ao mercado de trabalho. Quando as empresas são forçadas a admitir, tendem a cumprir a obrigação, alocando o deficiente em atividades ou setores marginais, agravando ainda mais, a situação de exclusão desta categoria de pessoas. As políticas públicas não devem ser baseadas em coação, mas na consolidação de uma cultura de inclusão pautada em ética e responsabilidade social corporativa.

É importante assinalar que o texto constitucional de 1988 , ao estabelecer as vagas reservadas destinadas aos portadores de deficiência física, não levou em consideração as condições pessoais dos portadores, mas sim, a capacidade de integração dessas pessoas na sociedade.

Isto porque, a deficiência não deve ser vista como sinônimo de ineficiência, de doença, de incapacidade, devendo o mercado de trabalho estar, permanentemente, aberto à inclusão, oportunizando aos deficientes que exerçam atividades laborais na medida em que sua limitação física permita.

As pessoas portadoras de deficiência são pessoas capazes, embora possuam determinadas limitações, sendo que o direito ao trabalho é um direito que lhes asseguram viver como as demais pessoas, mormente quando a atividade do trabalho tem a função de lhes possibilitar através de sua remuneração prover sua própria subsistência.

O Estado privilegia a cidadania e se fundamenta na garantia do exercício dos direitos humanos conferidos pela ordem jurídica, e submetido à lei deve estabelecer diretrizes de atuação assegurando medidas eficazes e o mínimo de bem-estar para as pessoas portadoras de deficiência.

Parece claro que todas as normas de proteção aos deficientes são na verdade normas de integração e inclusão: isonomia, integração e dignidade da pessoa humana, onde o respeito à dignidade reporta o respeito à igualdade necessária à integração social, e aí as normas intervêm criando uma igualdade fictícia onde não existe. Essa igualdade criada pela norma tem por objeto a real verificação da dignidade do homem. 
Além disso, a inclusão social dos deficientes traz benefícios para a coletividade, devendo o Estado assumir um papel mais ativo, promovendo ações inclusivas, bem como políticas públicas de conscientização para a diminuição dos preconceitos, possibilitando maior incentivo para os incluírem no mercado de trabalho, como também ações afirmativas, no sentido de demonstrar que os deficientes são pessoas capazes igualmente a qualquer outro ser que não possua nenhuma deficiência.

Sabemos que a inclusão do deficiente na sociedade é oriunda de uma lenta e gradual transformação, entretanto, podemos constatar que a sociedade conseguiu adquirir maturidade.

Aliada a isso, a inserção da pessoa com deficiência ao mercado de trabalho depende da qualificação do candidato e do interesse do empregador, sendo que o sistema legal de reserva de vagas acompanhado de medidas complementares que estimulem a contratação de pessoas deficientes, tornam-se eficientes, bem como os empregadores se mostram mais receptivos à contratação, motivo pelo qual, podemos concluir que o sistema de cotas deve estar associado a leis, programas de incentivos e instituições que possam facilitar a 932 inclusão da pessoa com deficiência no mercado de trabalho.

É importante assinalar, que a contratação de pessoas com deficiência não depende da função a ser desempenhada, mas do número de empregados na empresa, cabendo ao empregador determinar quais cargos podem ou devem ser preenchidos pelos empregados com deficiência, observadas as peculiaridades e limitações próprias de cada função, sendo que dificilmente todas as funções existentes demandarão capacidades tão específicas que impossibilitem totalmente o acesso e a inclusão da pessoa com deficiência no ambiente de trabalho e, caso a empresa deixe de cumprir o preenchimento das cotas estabelecidas no art. 93 da Lei n. ${ }^{\text {o }}$ 8.213/91 poderá ser autuada em eventual fiscalização.

A atuação do Ministério Público do Trabalho e do Ministério da Economia Secretaria de Trabalho na inclusão da pessoa com deficiência no mercado de trabalho buscam alterar o paradigma cultural da exclusão do mercado de trabalho das pessoas deficientes, sendo possível enfatizar que o desconhecimento da capacidade desta categoria de pessoas é o maior obstáculo ao cumprimento da legislação, sendo essencial a atuação 
destes órgãos para o sistema legal de reserva de vagas, representando meio eficaz de fiscalização o cumprimento da lei.

Ressalta-se, que ainda está enraizado o preconceito sobre a pessoa com deficiência para as empresas, uma vez que possuem a visão de que eles são incapazes de realizar um trabalho como qualquer outra pessoa sem deficiência, e mesmo com os sistemas de cotas garantido pela legislação infraconstitucional, algumas empresas não cumprem o esperado, sendo que as empresas que possuem grande números de funcionários estão sendo obrigadas a fazer a contratação para não sofrerem penas administrativas por parte do Ministério do Trabalho e Emprego.

Para alguns empregadores, a falta de informação e mão de obra qualificada para a contratação das pessoas com deficiência justifica a dificuldade de contratação, entretanto, devemos reconhecer que o sistema de cotas é um grande avanço, mas conforme os direitos constitucionais da pessoa humana, se todos são iguais perante a lei, qual a razão da existência de sistemas de cotas? A resposta é simples, justamente para forçar a sociedade a respeitar um direito que já é de direito do cidadão.

Portanto, não são as pessoas com deficiência que são diferentes e sim, o espaço e as condições impostas pelo sistema é que são desiguais quando se trata de igualdade de direitos e dignidade da pessoa humana, sendo necessário a introdução de políticas inclusivas, a fim de que as pessoas excluam a percepção primitiva de que mereçam um gesto de caridade, mas sim, sua inclusão no mercado de trabalho por oportunidades iguais, a fim de exercer a justiça social e o fortalecimento de uma das imprescindíveis balizas do Estado Democrático de Direito.

\section{CONCLUSÃO}

A pesquisa trouxe um novo olhar na perspectiva da luta da pessoa com deficiência em estar inserida no mercado de trabalho, passando por vários desafios, superando barreiras ao enfrentar as empresas capitalistas e a falta de respeito da sociedade civil organizada. 
A análise dos princípios constitucionais, em defesa da aplicabilidade direta do princípio constitucional da igualdade para a garantia dos direitos fundamentais do portador de deficiência, constata-se que o tratamento dos direitos das pessoas portadoras de algum tipo de deficiência tem como pressuposto o exame da Constituição Federal de 1988, traduzindo-se no conceito de sistema jurídico aberto de regras e princípios que sistematiza as regras necessárias para o equilíbrio das relações entre o Estado e os cidadãos e destes entre si, normas estas, impostas, coercitivamente, pelo poder público, de aplicação sobre todos os ramos da ciência jurídica.

Uma sociedade pluralista é matizada pela complexidade dos relacionamentos, em que as pessoas com deficiência possuem diversos impedimentos à integração, situando-se em contextos econômicos, culturais e sociais diferentes, vivenciando valores e padrões culturais próprios, possuindo necessidades específicas para a plena fruição de suas personalidades, e exigem cuidados distintos para que possam revelar suas próprias capacidades.

Ao longo do trabalho, restou demonstrado que os deficientes sofreram e ainda 934 sofrem diversas discriminações desde os primórdios, sendo em suas casas, no ambiente laboral, assim como na sociedade em geral, lutando para alcançarem a verdadeira isonomia em razão das suas limitações, sendo que essas pessoas devem ser tratadas desigualmente na medida das suas desigualdades.

É importante destacar que com a desenvolvimento da sociedade, as leis evoluíram em consonância com as suas necessidades, sendo que esse progresso acerca da inclusão decorreu em razão das lutas travadas por essa classe discriminada.

A Constituição Federal de 1988 foi o marco para a promoção de políticas de naturezas afirmativas, entretanto, a inclusão dos deficientes no mercado de trabalho dá-se maneira abstrusa, uma vez que a sociedade, infelizmente, ainda não os enxerga como seres capazes na medida de seus limites, sofrendo entraves em relação a essas pessoas, pois são vistas como incapazes, em razão das limitações físicas que possuem e afetam em seus aspectos cognitivos, o que não é verdade. 
Ressalta-se que o tema é ladeado de discriminações e desigualdades, pois embora os deficientes tenham conquistado mudanças legislativas, como o Estatuto da Pessoa com Deficiência ou a Lei de Cotas, ainda há muito o que ser conquistado, uma vez que alguns empregadores não possuem interesse em contratar os deficientes e/ou os contratam apenas para receber as benesses que a lei oferece.

Cumpre salientar, que é necessário políticas inclusivas para que as pessoas vejam as pessoas com deficiência como seres humanos, independente das suas limitações e não como indivíduos que mereçam um gesto de caridade.

Logo, é indispensável a conscientização por parte de todos, onde as pessoas possam entender que embora os deficientes possuam limitações, tais limites desde que não sejam cognitivos graves, não obstam quaisquer formas de inclusão no mercado de trabalho, devendo enxergar os deficientes como seres que possuem direitos e deveres e não satisfazerem-se com benefícios pecuniários, como aposentadorias fornecidas pelo Estado e acomodar-se.

A inclusão, no sentido forte da palavra, ainda está distante da realidade, 935 principalmente quando se trata de oportunidade de crescimento profissional, já que há o frágil raciocínio de que as empresas ofertem apenas oportunidade de emprego, nada mais.

Desta forma, as buscas pelas mudanças devem ser constantes, permitindo que esse cenário possa ser modificado e futuramente, alcançar a igualdade efetiva, através das garantias e direitos constitucionais, mediante a prática de adoção de políticas de inclusão, com o objetivo de afastar e reduzir as desigualdades, proporcionando às pessoas com necessidades especiais e/ou limitações, tratamento igualitário e integração no meio social e laboral.

\section{REFERÊNCIAS}

ALEXY, Robert. Teoria dos Direitos Fundamentais. 2.ed. São Paulo: Malheiros Editores, 2011.

ARAÚJO, Luiz Alberto David. Defesa dos Direitos das Pessoas Portadoras de Deficiência. Ed. Revista dos Tribunais, São Paulo, 2006. 
ARAUJO, Luiz Alberto David. O conceito de pessoas com deficiência e algumas de suas implicações no Direito brasileiro. Revista de Direito Constitucional e Internacional, vol. 86, p. I65-I8I, Jan-Mar, 2014 [recurso eletrônico]. Disponível em: http://www.revistadostribunais.com.br. Acesso em: 22 jun. 2020.

BAHIA, Claudio José Amaral; KOBAYASHI, Wilson. Os direitos da pessoa portadora de deficiência e a necessidade de cumprimento de pena em regime prisional. p.35-62. In: ARAUJO, Luiz Alberto David (Coord). Direito da pessoa portadora de deficiência: uma tarefa a ser completada. Baury: EDITE, 2003.

BOBBIO, Norberto. A Era dos Direitos. 19. reimp. Rio de Janeiro: Elselvier, 1992.

BOBBIO, Norberto. Igualdade e Liberdade. 4. ed. Tradução Carlos Nelson Coutinho. Rio de Janeiro: Ediouro, 200o.

CASSAR, Vólia Bomfim. Direito do trabalho. ıo. ed. São Paulo: Método, 2014.

COSTALLAT, Fernanda Lavras. O direito ao trabalho da pessoa deficiente: manual de orientação: legislação e jurisprudência. Fundação Síndrome de Down, 2003.

DELGADO, Mauricio Godinho. Curso de Direito do Trabalho. Editora LTr, 12 a Edição. São Paulo, 2013.

FARIAS, Cristiano Chaves; CUNHA, Rogério Sanches; PINTO, Ronaldo Batista. Estatuto da Pessoa com Deficiência. 2. rev. Salvador: Ed. JusPodvm, 2016.

FERREIRA FILHO, Manoel Antonio. Comentários à Constituição Brasileira: Emenda Constitucional n. ${ }^{\circ}$ I, de I7-I0-1969, com as alterações introduzidas pelas Emendas Constitucionais até a de n. ${ }^{\mathrm{o}}$ 27, de 27-II-1985, 6⿳a ed. São Paulo: Saraiva, 1986.

FOUCAULT, Michel. DECLARAÇÃO DE SALAMANCA: Sobre Princípios, Políticas e Práticas na Área das Necessidades Educativas Especiais, Salamanca-Espanha, 1994.

GOMES, Joaquim B. Barbosa. Ação afirmativa e o princípio constitucional da igualdade: o direito como instrumento de transformação social: a experiência dos EUA. Rio de Janeiro: Renovar, 200I.

JUNIOR, Vidal Serrano Nunes / ARAUJO, Luiz Alberto David. Curso de Direito Constitucional. 21 ${ }^{\mathrm{a}}$ Edição. 2017. Editora Verbatim.

LEITE, Carlos Henrique Bezerra. Curso de direito de trabalho. 8. ed. São Paulo: Saraiva, 2017 .

MELlO, Marco Aurélio Mendes de Faria. "Ótica Constitucional: A igualdade e as ações 
afirmativas". Brasília, 200I, p. 159. Disponível em: https://hdl.handle.net/20.500.12178/110316. Acesso em: 25 jun. 2020.

MENDES, Gilmar Ferreira; BRANCO, Paulo Gustavo Gonet. Curso de Direito Constitucional. Io ${ }^{\mathrm{a}}$. ed. rev. e atual. São Paulo: Saraiva, 2015.

MIRANDA, Pontes de. Comentários à Constituição de 1967: com a Emenda n. I, de 1969. 2ª ed. São Paulo: Revista dos Tribunais, 1972.

PIOVESAN, Flávia. Direitos humanos e o direito constitucional internacional: prefácio de Henry Steiner; apresentação de Antônio Augusto Cançado Trindade. I8 ed. rev. e atual. São Paulo: Saraiva Educação, 2018.

PIOVESAN, Flávia. Ações afirmativas da perspectiva dos Direitos Humanos. Disponível em: $\quad$ http://www.scielo.br/scielo.php?pid=SorooI5742005000100004\&script=sci_abstract\&tlng=pt. Acesso em: 26 jun. 2020.

ROCHA, Salete Casali. Direitos Humanos e Diversidade. Grafisul, Francisco Beltrão, 2015 .

ROTHENBURG, Walter Claudius. Direitos Fundamentais. Ed. Método, 2014. Iㄴ ed., São Paulo.

SARLET, Ingo Wolfgang. Dignidade da Pessoa Humana e Direitos Fundamentais - na Constituição Federal de 1988. 8ª̣ed. Porto Alegre: Livraria do Advogado, 2010.

SASSAKI, Romeu Kasumi. Inclusão: Construindo uma Sociedade para Todos. Rio de Janeiro: WVA, 1997.

SILVA NETO, Manoel Jorge e. Proteção constitucional dos interesses trabalhistas difusos, coletivos e individuais homogêneos. São Paulo, LTr, 200I, p. 52.

WERNECK, Cláudia. A humanidade como ela é. 20or. Disponível em: http://www.educacional.com.br/entrevistas/entrevistaoo73.asp. Acesso em 28 set 2020. 